\title{
Host-directed antiviral therapies - an emphasis on hiv post-exposure prophylaxis
}

Volume 4 Issue 2 - 2016

Keywords: Host-directed therapies, Antivirals, HIV postexposure prophylaxis, Immune dysregulation, HIV occupational exposure, Non-occupational exposure

\section{Introduction and Background}

Infectious diseases are the leading cause of mortality and morbidity worldwide and include bacterial, viral, fungal and parasitic infections. ${ }^{1}$ The emergence of novel zoonotic pathogens together with the increasing incidence of treatment-resistant infections and diseases, has given rise to the need for alternative and different treatment strategies. ${ }^{1}$ Host-directed antiviral therapy is a new concept within the modern medicine era and most literature data is based on multiple-drug resistance tuberculosis (TB) strains. ${ }^{2}$ These hostdirected therapies are products that can enforce or enhance the host's defence mechanisms or play an active role in modulating excessive host inflammatory responses. ${ }^{3}$ It must be understood that hostpathogen interactions are dependent on the causative microbe actually surviving without causing any harm or damage to the host. In turn, host factors can affect deliberate treatment outcomes, namely through the following categories:

\section{Immune dysregulation}
a. Stress
b. Malnutrition
c. Immunosuppression

\section{Co-morbidities}

a. Cancers

b. Diabetes mellitus

c. Chronic obstructive pulmonary disease (COPD) (4).

It is well-established that any infection may subside or progress to disease or the ultimate consequence of death and this depends on the innate and adaptive immune response. ${ }^{5}$ Host-directed therapies have the following actions and mechanisms, namely:

a. Improvement and enhancement of the host cellular responses to pathogens;

b. Targeting the disease process that causes and stimulates virulence factors;

c. Activation of the repertoire of immune responses and by

d. Activating the status of immunological memory. ${ }^{6}$

Host-directed therapies also evoke macrophage responses inducing free radicals, antimicrobial peptides, cytokines, chemokines, prostaglandins, autophagy and apoptosis. ${ }^{7}$

\author{
Lynne Margaret Webber \\ Department of Medical Virology, University of Pretoria, South \\ Africa
}

Correspondence: Lynne Margaret Webber, Department of Medical Virology, University of Pretoria, Consultant Pathologist and Clinical Virologist, National Health Laboratory Service (NHLS), Tshwane Academic Division (TAD), Private Bag: X323 Arcadia, Pretoria, South Africa, Tel +2712 3192565 , Fax +27I2 3255550 Email lynne.webber@up.ac.za

Received: December 0I, 2016 | Published: December 05, 2016

There are many different types of host-directed therapies and include the following products and agents, namely:

a. Affordable and commonly used drugs for non-communicable diseases that show a reliable and good safety profile;

b. Cellular therapies that use the patient's immune system or their mesenchymal stromal cells;

c. Nutritional commercial products;

d. Immunomodulatory agents and

e. Biological products. ${ }^{8}$

Table 1 lists certain viral infections that are treated with hostdirected products. ${ }^{9-14}$

Table I Viral Infections Treated with Host-Directed Antiviral Therapies 9 -14

\begin{tabular}{ll}
\hline MERS & $\begin{array}{l}\text { Middle East Respiratory Syndrome Coronavirus - } \\
\text { Previously Known as a Novel Coronavirus }\end{array}$ \\
\hline HCV & Hepatitis CVirus \\
EBV & Epstein-Barr Virus of the Herpes Virus Family \\
HIV & Human Immunodeficiency Virus Types one and two \\
Dengue Virus & $\begin{array}{l}\text { An Arthropod-Borne Virus that can Exhibit Viral } \\
\text { Haemorraghic Fever Signs }\end{array}$ \\
CMV & $\begin{array}{l}\text { Cytomegalovirus of the Herpes Virus Family } \\
\text { Adenovirus }\end{array}$ \\
A Virus Exhibiting Diverse Clinical Signs and Symptoms \\
Influenza & $\begin{array}{l}\text { A Respiratory-Borne Virus of Multiple and Emerging } \\
\text { Strains }\end{array}$ \\
Ebola Virus & A Viral Haemorraghic Virus confined to Specific \\
& Geographic Regions
\end{tabular}




\section{Human Immunodeficiency Virus (HIV) and Post-Exposure Prophylaxis}

HIV is a retroviral disease that can be transmitted sexually, vertically from mother to child and through blood and blood products and many other body fluids. ${ }^{15,16}$ To date there is no fully effective vaccine against HIV and treatment consists of a combination with three antiretroviral drugs. There are different classes of antiretroviral drugs and selected regimes of treatment are proposed. ${ }^{17}$ Currently, there are research studies into other modalities of HIV treatment, namely:

a. Monoclonal antibodies, such as the example of anti-PD-1 that activates and mobilizes antigen-specific T-cells. These T-cells create an immune checkpoint blockade that can suppress the HIV-1 RNA viral load. ${ }^{18}$ and

b. Cellular therapy: mesenchymal stromal cells reduce the destructive actions of the inflammatory response and in turn these stromal cells also enhance tissue and organ repair. ${ }^{19}$

Table 2 shows a summary of recommendations for post-exposure prophylaxis for HIV exposure in adults and adolescents. ${ }^{20}$ There are three broad approach categories to the recommendations for postexposure prophylaxis, namely the clinical approach, the antiretroviral drug selection and community health issues. ${ }^{21}$

Table 2 Post-Exposure for Adults and Adolescents

HIV post-exposure drug regimen should be a combination of three antiretroviral drugs

A full one month course of antiretroviral drugs should be prescribed

The post-exposure antiretroviral drugs should be prescribed as soon as possible after the exposure (at initial assessment wherever possible) Starter packs containing drugs for a limited number of days should not be uniformly accepted for full coverage for post-exposure management Follow up management is essential

Exposed individuals should be seen and examined at regular intervals, such as at 2 weeks, 6 weeks, 3 months and up to 6 months post-exposure

Adherence counselling should be initiated and sustained.

Clinically, the exposed individuals should complete the full course of drug prescription, should be aware of and counselled to manage the drug side-effects and should also receive additional counselling for any resultant emotional problems.

Drug selection should be a three drug regimen and pregnant women should be managed according to the drug safety instructions in pregnancy. Education and community awareness should be encouraged.

\section{Conclusion}

Occupational exposures can be minimised by following stringently health and safety precautions (universal safety precautions). Safety and post-exposure prophylaxis protocols should be accessible and regularly reviewed. Hepatitis B vaccination programmes must be in place and education about the programme should be sustained.

\section{Acknowledgments}

None.

\section{Conflicts of interest}

None.

\section{References}

1. Zumla A, Rao M, Wallis RS et al. Host-directed therapies for infectious diseases: current status, recent progress, and future prospects. Lancet Infect Dis. 2016;16(4):47-63.

2. Robertson KR, Robertson WT, Ford S et al. Highly active antiretroviral therapy improves neurocognitive functioning. J Acquir Immune Defic Syndr. 2004;36(1):562-566.

3. Brown JMY Exogenous administration of immunomodulatory therapies in hematopoetic cell transplantation: an infectious diseases perspective. Current Opinionin Infect Dis. 2005;18(4):352-358.

4. Wohl DA, Zeng D, Stewart $\mathrm{P}$ et al. Cytomegalovirus viremia, mortality and end-organ disease among patients with AIDS receiving potent antiretroviral therapies. $J$ Acquir Immune Defic Syndr. 2005;38(5):538-544.

5. Palella FJ, Delaney KM, Moorman AC et al. Declining morbidity and mortality among patients with advanced human immunodeficiency virus infection. HIV Outpatient Study Investigators. $N$ Eng $J$ Med. 1998;338(13):853-860.

6. Robertson KR, Smurzynski M, Parsons TD et al. The prevalence and incidence of neurocognitive impairment in the HAART era. AIDS. 2007;21(14):1915-1921.

7. Kaul M, Lipton SA Chemokines and activated macrophages in HIV gp 120-induced neuronal apoptosis. Proc Natl Acad Sci USA. 1999 ;96(14):8212-8216.

8. Viral Structure, Classification, and Replication. Clinicalgate. 2015

9. Prescott J, Bushmaker T, Fischer R et al. Postmortem stability of Ebola virus. Emerg Infect Dis. 2015;21(5):856-859.

10. Boone SA, Gerba CP. Significance of fomites in the spread of respiratory and enteric viral disease. Appl Environ Microbiol. 73(6):1687-1696.

11. Alter MJ (2002) Prevention of the spread of hepatitis C. Hepatology 36(Suppl 1): S93-S98.

12. Stowell JD, Forlin-Passoni D, Din E et al. Cytomegalovirus survival on common environmental surfaces: opportunities for viral transmission. $J$ Infect Dis. $2011 ; 205(2): 211-214$.

13. Thomas Y, Vogel G, Wunderli W et al. Survival of influenza on banknotes. Appl Environ Microbiol. 2008;74(10):3002-3007.

14. Amellal B, Murphy R, Maiga A et al. Stability of HIV RNA plasma in plasma specimens stored at different temperatures. HIV Med. 2008 ;9(9):790-793.

15. Price RW, Brew BJ The AIDS dementia complex. J Infect Dis. 1988;158(5):1079-1083.

16. Harezlak J, Buchthal S, Taylor M et al. Persistence of HIV-associated cognitive impairment, inflammation and neuronal injury in era of highly active antiretroviral treatment. AIDS. 2011;25(5):625-633.

17. Southern African HIV Clinicians Society. Post-exposure prophylaxis. $S$ Afr J HIV Med. 2008;9(3):36-45.

18. Topalian SL, Hodi FS, Brahmer JR et al. Safety, activity and immune correlates of anti-PD-1 antibody in cancer. $N$ Eng J Med. 2012 ;366(26):2443-2454.

19. Uccelli A, Moretta L, Pistoia V Mesenchymal stem cells in health and disease. Nat Rev Immunol. 2008;8(9):726-736.

20. Guideline on the management of occupational and non-occupational exposure to the human immunodeficiency virus and recommendations for post-exposure prophylaxis: 2015

21. update. http://www.sajhivmed.org.za/doi:10.4102/sajhivmed.v16i.399.

22. Bell DM Occupational risk of human immunodeficiency virus infection in healthcare workers: an overview. Am J Med. 1997;102(5B):9-15. 